\title{
PERIPHERAL NERVE STIMULATOR PERFORMANCE: THE INFLUENCE OF OUTPUT POLARITY AND ELECTRODE PLACEMENT
}

\author{
Henry Rosenberg and D. Eric Greenhow
}

The Peripheral Nerve stimulator has achieved an accepted place in the practice of anaesthesia to monitor neuromuscular function. Contraction of the fingers is usually elicited by placement of stimulating electrodes over the course of the ulnar nerve at the wrist or elbow.' However, transcutaneous stimulation of the ulnar nerve at the wrist is not always effective in eliciting muscle movement, particularly when surface electrodes are employed.

The purpose of this communication is to demonstrate how electrode placement as well as polarity of the nerve stimulator output can affect the performance of the peripheral nerve stimulator.

\section{Methods}

The polarity of the output of a specially designed peripheral nerve stimulator ( $35 \mathrm{~V}$ output at $1000 \Omega ; 70$ volts at $10,000 \Omega$; square wave output at $0.5 \mathrm{msec}$ duration, $50 \mathrm{hz}$ tetanus) was identified with the aid of an ascilloscope. *

In a patient anaesthetized with nitrous oxide and halothane without relaxants, four surface (Ferris Red Dot ${ }^{\circledR}$ ) electrodes and one 23-gauge needle electrode were placed at several sites on the upper extremity (Figure 1). The electrodes were positioned so as to approximate ulnar nerve stimulation at the wrist and elbow and median nerve stimulation at the wrist. The radial aspect of the forearm was chosen as an indifferent site. The leads of the stimulator were attached to the electrodes in various combinations. Adduction of

Henry Rosenberg, M.D., Assistant Professor of Anesthesia and Pharmacology. D. Eric Greenhow, M.D., Assistant Professor of Ane sthesia, University of Pennsylvania School of Medicine.

This work was performed at the Hospital of the University of Pennsylvania, 3400 Spruce Street, Philadelphia, PA, 19104.

Supported in part by grants USPHS GM 15430-10 and GM00215-20.

Address correspondence to Henry Rosenberg, M.D.

* Identification of the output polarity can also be done by attaching the stimulator leads to lead I of a standard ECG device. An upward deflection on the ECG trace indicates that the positive stimulator lead is connected to the right arm ECG lead.

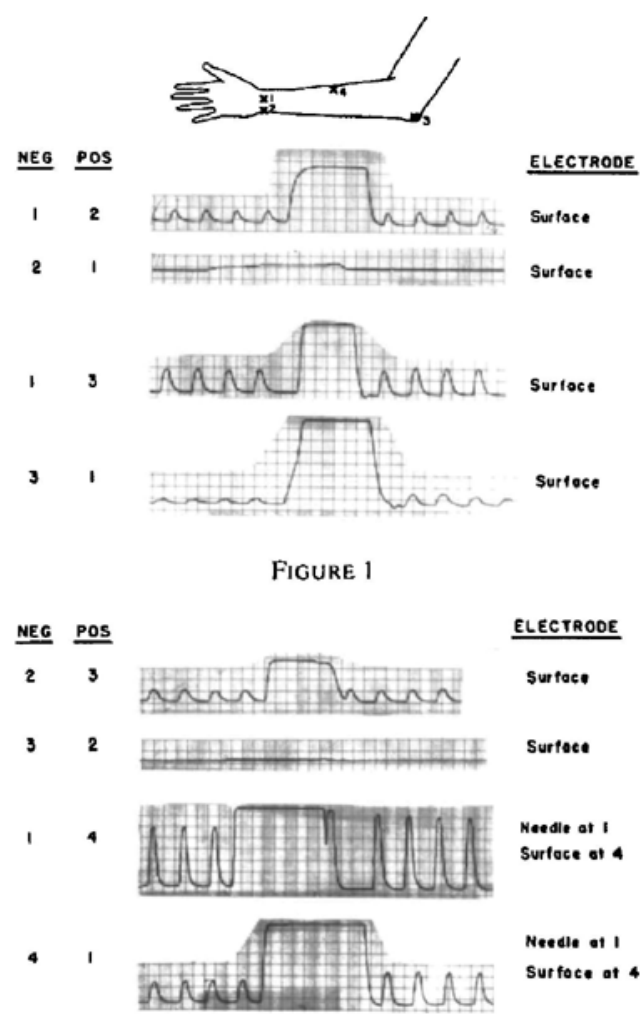

Figure 2

FIGURES 1 and 2. Recording of the thumb adduction upon neural stimulation via surface or needle electrodes in a patient anesthetized with nitlous oxide and halothane. The strength of contraction depends on electrode placement and polarity (see text for further details).

the thumb was assessed with a Grass FT-10C force transducer ${ }^{2}$ upon stimulation at 0.5 and $50 \mathrm{hz}$.

\section{RESULTS}

In this patient, using surface electrodes, movement of the thumb was most marked when the negative pole of the nerve stimulator was connected to the electrode over the middle of the volar aspect of the wrist (median nerve stimula-

Canad. Anaesth. Soc. J., vol. 25, no. 5, September 1978 
TABLE I

muscles Concerned With Finger flexion, adduction, and Abduction InNervated By the Ulnar and Median Nerves ${ }^{3}$

\begin{tabular}{lc}
\hline Hand (Volar surface) & Forearm \\
\hline Ulnar nerve & Ulnar nerve \\
Adductor pollicis & Flexor carpi ulnaris \\
Abductor digiti minimi & Flexor digitorum profundus \\
Flexor digiti minimi brevis & Median \\
Opponens digiti minimi & Flexor carpi radials \\
Lumbricales (medial 2) & Palmaris longus \\
Interossei palmaris & Flexor digitorum superficialis \\
Median & Flexor digitorum profundis \\
Abductor pollicis brevis & Flexor pollicis longus \\
Opponens pollicis & \\
Flexor pollicis brevis & \\
Lumbricales (lateral 2) & \\
\hline
\end{tabular}

tion). Cathodal stimulation at the lateral aspect of the wrist produced virtually no thumb movement. Stimulation at the ulnar groove produced hand adduction predominantly.

Using the subcutaneous needle electrode, ulnar stimulation at the wrist was more effective in producing thumb adduction than was median nerve stimulation. The effect of polarity was still obvious, however, in that greater contractile strength was seen upon cathodal stimulation at the wrist.

\section{Discussion}

Although the peripheral nerve stimulator is usually recommended in the evaluation of neuromuscular function, optimum placement of the stimulating electrodes is rarely discussed. Usually, stimulation of the ulnar nerve is recommended since the nerve innervates most of the adductors of the thumb and flexors of the fingers.' However, the median nerve is also motor to several adductors and the opponens muscles of the thumb and fingers (Table I). At the wrist, the median nerve is a larger nerve than the ulnar and in theory may be stimulated more easily from surface electrodes. Ulnar stimulation at the elbow may elicit finger flexion, but sometimes only gross hand movement at the wrist may occur due to predominance of flexor carpi ulnaris stimulation. Therefore, stimulation of the median nerve should be considered for the production of finger flexion when using the peripheral nerve stimulator.

The polarity of the stimulating electrode is important (Figures $1 \& 2$ ). Optimally the negative pole should be placed over the nerve to be stimulated. ${ }^{4}$ Similarly, in using the peripheral nerve stimulator as an aid to performing nerve blocks, ${ }^{5}$ the negative pole of the stimulator should be connected to the exploring needle. Nerve stimulation can be achieved at a lower voltage than when the anode is connected to the exploring needle.

In practice, if the lead polarity of the stimulator is unknown, reversing the connections will reverse the polarity and may thereby enhance or diminish the muscle response.

When using surface electrodes that have a fixed distance between the electrodes, their placement over median and ulnar nerves at the wrist is suggested. If this is not effective in producing finger movement, one electrode should be placed over the ulnar nerve at the elbow, with the other over the median nerve at the wrist. Increasing the distance between electrodes increases the impedance, and the voltage output of most peripheral nerve stimulators.

\section{SUMMARY}

The median as well as the ulnar nerve may be used effectively in the evaluation of neuromuscular blockade with the peripheral nerve stimulator. Both ulnar and median nerve stimulation produce flexion of the fingers. For maximum neural stimulation either during the routine use of the peripheral nerve stimulator or when it is used as an aid to peripheral nerve block, the negative pole should be attached to the exploring needle or over the nerve to be stimulated.

\section{RÉSUMÉ}

Le nerf médian, tout comme le cubital (que l'on utilise habituellement), peut ètre utilisé pour 
évaluer un bloc neuro-musculaire avec un stimulateur nerveux périphérique. La réponse à la stimulation de l'on ou de l'autre nerf est une flexion des doigts. Le pôle négatif devrait être placé de routine sur l'électrode exploratrice ou sur le nerf à stimuler, ce qui permet d'obtenir une stimulation maximale.

\section{REFERENCES}

1. Katz, R.L., Wolf, C.F., \& Popper, E.M. The non-depolarizing neuromuscular blocking action of succinylcholine in man. Anesthesiology 24: 784 (1963).

2. WALTS, L.F., Lebowitz, M., \& Dillon, J.B. A means of recording force of thumb adduction. Anesthesiology 29: 1054 (1968).

3. QUIRING, D.P. \& WARFEL, J.M. The extremities. Philadelphia: Lea \& Febiger, pp. 31-61 (1960).

4. Montgomery, S.J., Ray, P.P., Nettles, D., \& JENKINS, M.T. The use of the nerve stimulator with standard unsheathed needles in nerve blockade. Anesthesia and Analgesia 52: $827-831$ (1973).

5. Brobeck, J.R. Best and Taylor's Physiological Basis of Medical Practice, $91 \mathrm{~h}$ ed. Baltimore: Williams \& Wilkins Co., pp. 1-39 (1973). 